\title{
BOND STRENGTH OF WHITETOPPINGS AND BONDED OVERLAYS CONSTRUCTED WITH SELF- COMPACTING HIGH-PERFORMANCE CONCRETE
}

Rubén-Daniel López-Carreño ${ }^{\mathrm{a},{ }^{*}}$, Pablo Pujadas ${ }^{\mathrm{a}}$, Sergio H. P. Cavalaro ${ }^{\mathrm{a}}$ and Antonio Aguado ${ }^{\mathrm{a}}$

a Department of Civil and Environmental Engineering, Universitat Politècnica de Catalunya Barcelona Tech, Jordi Girona 1-3, C1, E-08034 Barcelona, Spain

* Corresponding authors at: Department of Civil and Environmental Engineering, Universitat Politècnica de Catalunya Barcelona Tech, Jordi Girona 1-3, C1, E-08034 Barcelona, Spain. Email address: ruben.daniel.lopez@upc.edu (R.D. López), Tel: +34 934016507 Fax: +34 934011036

\section{ABSTRACT}

A bonded concrete overlay consists of a concrete layer poured over a deteriorated pavement. Its mechanical performance depends on the quality of the bond between the lower and the uppermost layers. This paper reports an extensive experimental program to evaluate bond strength between Conventional Concrete (CC) and Asphalt Concrete (AC) substrates and Self-Compacting High-Performance Concrete (SCHPC) overlays. In all, 8 interface treatments are tested under Direct Tension, pure shear "LCB", and compressive Slant Shear tests. The results show that direct pouring of the SCHPC overlay over CC and AC substrates produces similar or higher strengths than the other treatments analyzed.

KEYWORDS: Whitetopping, Concrete Overlays, Pavements, High-Performance Concrete, Bond Strength

\section{INTRODUCTION}

Over recent years, highway agencies have invested immense effort in successful maintenance strategies for their road networks, despite tighter budgets, increased traffic volumes and loads, and the critical focus that has emerged on pavement sustainability and conservation [1]. In many pavement conservation activities, resurfacing with a bonded concrete overlay may represent a more cost-effective, rapidly constructed, and sustainable solution than full reconstruction [2].

When placing the concrete layer over an asphaltic (whitetopping) or a Portland cement concrete (overlay) pavement, the bond strength between substrate and the upper layer plays a crucial role in the mechanical behaviour of the composite pavement. Thinner overlays are possible, as the bond ensures a 
monolithic response under stress [3]. Additionally, the inherent self-compacting behaviour of SelfCompacting High-Performance Concretes (SCHPC) can further reduce resurfacing thicknesses and increase bonding strength [4]. SCHPC overlays may therefore be placed on pavements with height limitations such as tunnels, underpasses, and urban streets where levels are restricted by sidewalks, drains, manhole covers, etc. Furthermore, the use of SCHPC can also reduce the long-term economic cost of pavement maintenance [5]

Table 1 summarizes some of the works reporting laboratory tests that characterize the bonding strength between substrate layers of both Asphalt Cement (AC) and Conventional Concrete (CC) made of Portland cement and concrete top layers at different compressive strengths $\left(f_{c k}\right)$. These experimental programs comprise tests for assessing bond strengths under pure tension, pure shear and combinations of normal and shear stresses. Note that there are no experimental programs that differentiate between those types of substrate. Furthermore, in the case of AC substrates, the authors have found no investigations on whitetopping bond characterizations with $f_{c k}>60 \mathrm{Mpa}$, nor experimental programs that combine tests to assess pure tension, pure shear and combined normal-shear stresses.

Table 1. Summary of studies reporting laboratory tests that characterize bonding strengths between AC and CC substrates and concrete overlays.

\begin{tabular}{|c|c|c|c|c|c|c|c|}
\hline \multirow{2}{*}{ Reference } & \multicolumn{2}{|c|}{ Substrate Material } & \multicolumn{2}{|c|}{ Uppermost Concrete Layer } & \multicolumn{3}{|c|}{ Tests } \\
\hline & $\mathrm{AC}$ & $\mathrm{CC}$ & $\mathrm{f}_{\mathrm{ck}} \leq 60 \mathrm{MPa}$ & $\mathrm{f}_{\mathrm{ck}}>60 \mathrm{MPa}$ & Pure tension & Pure shear & $\begin{array}{c}\begin{array}{c}\text { Combined } \\
\text { stresses }\end{array} \\
\end{array}$ \\
\hline$[6,7]$ & & • & - & & • & & \\
\hline [8] & & • & • & & & • & \\
\hline [4] & & • & • & & & & • \\
\hline [9] & & • & $\bullet$ & & • & & $\bullet$ \\
\hline [10] & & • & - & & • & • & • \\
\hline [11] & & • & • & • & • & & \\
\hline [12] & & • & & - & & & • \\
\hline$[13]$ & & • & & • & • & & • \\
\hline$[14,15]$ & & • & & • & • & • & • \\
\hline [16] & • & & • & & & • & \\
\hline$[17,18]$ & • & & • & & & & • \\
\hline [19] & • & & • & & • & & \\
\hline This Study & • & - & & - & - & • & • \\
\hline
\end{tabular}

The absence of experimental studies with both $A C$ and CC substrates make it difficult to ascertain whether a particular concrete mix can achieve sufficient bonding strength with these two materials; a 
situation that may occur in real-life situations, where resurfacing maintenance is planned for a road with both types of pavements. There is moreover a lack of knowledge on the bonding strength of SCHPC poured over AC layers, because no previous experimental tests exist on the matter.

The main objective of this work is to characterize and compare the bond strength obtained under different stress configurations with diverse interfacial treatments in whitetoppings and overlays constructed with SCHPC. To do so, an extensive experimental program is reported in this paper conducted with the two types of substrate materials (CC and AC), SCHPC overlays and 8 interface treatments (4 for CC and 4 for AC substrates). The specimens were tested under "pure" tensile and "pure" shear stresses and combined compression-shear stresses with Direct Tensile (DT), guillotine "Laboratorio de Caminos de Barcelona" (LCB) and compressive Slant Shear (SS) tests, respectively.

\section{REVIEW OF EXPERIMENTAL BOND-STRENGTH TESTS}

The interfaces between pavement layers are constantly exposed both to normal $(\sigma)$ and to shear stresses $(\tau)$. The debonding of an interface may occur due to three different stress situations: pure tension, pure shear and mixed situations with a combination of shear and compressive or tensile stresses [17, 20, 21]. Different tests are found in the literature to study these cases of debonding under static loads.

Table 2 summarizes the type of tests according to the type of stresses produced along the interface (pure tension, pure shear and mixed mode). Based on a previous work by Espeche \& León [11], the table includes three additional tests for mixed mode failure.

Pure tension stresses may be generated directly $(a, b)$ or indirectly $(c, d)$, depending on whether the load direction is parallel or normal to the stresses, respectively. Pure shear strength may be evaluated by inducing torsion (e) or shear stresses (f, g, h, l, j, k, I). As Espeche \& León [11] mentioned, "pure shear" is a theoretical situation that these tests are a long way from reproducing, because they induce a bending moment.

The mixed mode is a combination of normal and shear stresses. Espeche \& León [11] mentioned combined compression and shear tests $(m, n)$, although tests to induce shear and tensile stresses (o) in 
concrete-to-concrete specimens are also found in literature [22]. Bending tests $(p, q)$ have recently been used for bonding characterization between cement-based layers [23-25] and between asphalt and Portland cement concretes $[17,18,26]$.

Table 2. Test for assessing bond strength (based on [11]).

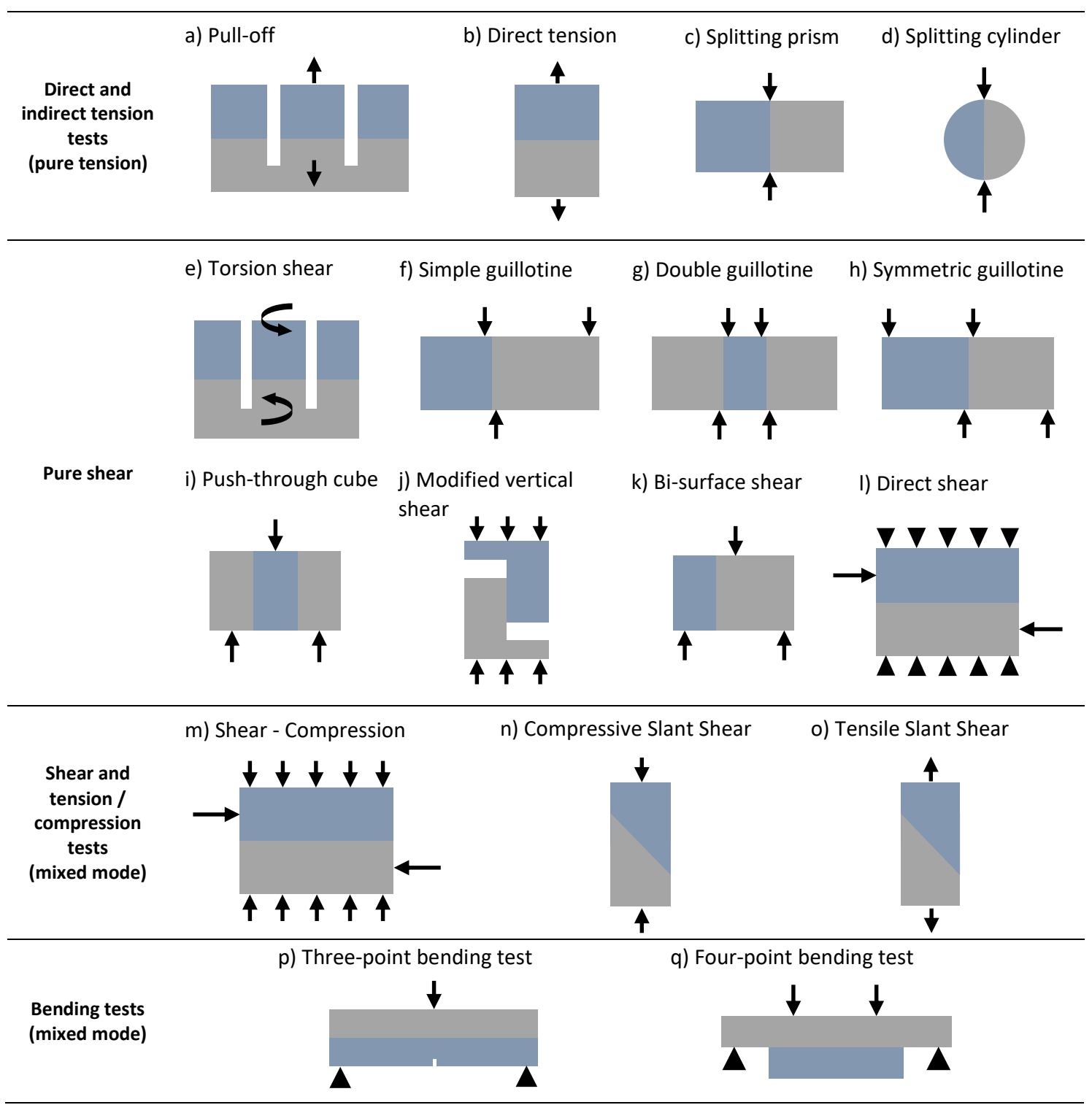

3. EXPERIMENTAL PROGRAM

Figure 1 shows the 2 variables considered in this experimental study: the substrate material (Conventional Concrete $(\mathrm{CC})$ And Asphalt Concrete $(\mathrm{AC})$ ) and the treatment applied to the interface between substrates and overlays. 4 treatments were studied for each of the substrate materials. A "XYY" 
code is used to identify the 8 cases, where " $X$ " refers to the substrate (C for Conventional Concrete and A for Asphalt Concrete) and "YY" refers to the interface treatment.

\section{< Insert Figure 1 >}

The appearances of all treatments are gathered in Figures 2.a - 2.g. For CC specimens the treatments were: (i) no preparation of the surface (CNP) where chemical bonding is obtained by pouring the fresh upper layer of Self-Compacting High-Performance Concrete (SCHPC) onto the smooth interface (Figure 2.a); (ii) spreading a cement paste over the smooth surface (CCP) (Figure 2.b); (iii) bush-hammering the interface $(\mathrm{CBH})$ for increased roughness (Figure 2.c); and, (iv) bush-hammering and subsequent extension of a cement paste (CBC) (Figures 2.b and c).

\section{< Insert Figure 2 >}

The AC treatments were: (v) no preparation of the surface (ANP) with the SCHPC poured over the leveled but porous surface (Figure 2.d); (vi) bush-hammering the interface (ABH) (Figure 2.e); (vii) extending a bituminous emulsion ( $A B E$ ) that fills the pores (Figure 2.f); and, (viii) spreading a bituminous emulsion and then placing gravel over the bitumen (AEG) to provide a new rough surface with no partial removal of material (Figure 2.g).

The characterization of the mechanical strength of the interfaces was performed with three types of tests. A "pure" tension condition was evaluated through Direct Tension tests (DT). The "Laboratorio de Caminos de Barcelona" (LCB) test $[27,28]$ was used to assess the "pure" shear strength. Finally, a combined situation of shear and compressive stresses was studied with compressive Slant Shear tests (SS). Results were compared between them to determine qualitatively the best interfacial treatments.

In total, 72 specimens with CC substrates were tested, amounting to 6 specimens for each type of surface treatment and test. The number of specimens tested with AC substrates amounted to 56 . This number is the sum of 12 specimens ( 6 for DT and 6 for LCB tests) for each 4 treatments and 8 specimens for SS tests (4 ANP, $3 \mathrm{ABH}$ and $1 \mathrm{ABE}$ ). The lack of SS specimens resulted from the difficulty of compacting the AC substrates with a shear surface and might indicate that this test is not especially suitable for AC substrate specimens. 


\subsection{Materials}

A semi-dense Asphalt Concrete (AC) for wearing courses was employed (see Table 3), designated as AC 16 SURF according to UNE-EN 13108-1:2008 [29]. It contained 50/70 bitumen (according to UNE-EN 12591:2009 [30]) and its Marshall density was $2.330 \mathrm{~kg} / \mathrm{m}^{3}$. The density of $48 \Phi 100 \times 100 \mathrm{~mm}$ cylindrical substrates was measured, obtaining an average Marshall density value of $94.1 \%$ with a variation coefficient of $3.28 \%$. Although $97 \%$ of the Marshall reference is commonly required for road constructions, the density achieved in the present work is considered acceptable.

The materials and mixture proportions of CC and SCHPC are shown in Table 4. The Conventional Concrete (CC) was designed taking as a reference the mix of the wearing layer of a real bi-layer concrete pavement constructed in northeastern Spain [31]. Limestone aggregates with the same minimum and maximum sizes described in [31] were used and the proportion between components was maintained.

Table 3. Mix proportion of AC.

\begin{tabular}{lc}
\hline \multicolumn{1}{c}{ Material } & \% by weight \\
\hline Granite gravel 12/20 mm & $13.0 \%$ \\
Granite gravel 4/12 mm & $45.0 \%$ \\
Limestone aggregate 0/4 mm & $39.0 \%$ \\
Limestone filler & $3.0 \%$ \\
Bitumen 50/70 (of the mixture) & $4.8 \%$ \\
\hline
\end{tabular}

The SCHPC mixture was designed, considering common recommendations such as high cement content, small size of coarse aggregate and low water-cement ratio (apparent water/cement ratio $=0.16$ ). Additionally, treated limestone micro-filler was included to improve workability, the packing of the granular skeleton and the cementitious matrix.

The mechanical properties of AC, CC and SCHPC are given in Table 5. In the case of AC, the compressive $\left(f_{a c}\right)$ and indirect tensile $\left(f_{a c t, i}\right)$ strengths were estimated through standards NLT-161/98 [32] and NLT-346/90 [33], respectively. A static modulus of elasticity ( $\left.E_{a c, e s t}\right)$ was estimated with the recorded piston displacements in $f_{a c}$ tests, calculated as the slope of the strain-stress curve under stresses of $25 \%$ and $75 \%$ of maximum strengths. 
Table 4. Mix proportions of CC and SCHPC.

\begin{tabular}{|c|c|c|c|}
\hline Material & $\begin{array}{l}\text { Content } \\
\left(\mathrm{kg} / \mathrm{m}^{3}\right)\end{array}$ & Material & $\begin{array}{l}\text { Content } \\
\left(\mathrm{kg} / \mathrm{m}^{3}\right)\end{array}$ \\
\hline Limestone sand $0 / 2 \mathrm{~mm}$ & 510 & Silica aggregate $2 / 4 \mathrm{~mm}$ & 1.161 \\
\hline $\begin{array}{l}\text { Limestone coarse aggregate } 4 / 11 \\
\mathrm{~mm}\end{array}$ & 1.190 & $\begin{array}{l}\text { Treated limestone powder OMYA } \\
\text { Betoflow }\end{array}$ & 200 \\
\hline Cement CEM II /A-L 42,5R & 480 & Cement CEM I 52,5R & 800 \\
\hline Water & 195 & Water & 129 \\
\hline \multirow[t]{2}{*}{ Superplasticizer SIKA Sikament-200 R } & \multirow[t]{2}{*}{2,15} & $\begin{array}{l}\text { Nano-silica suspension BASF } \\
\text { MasterRoc MS } 685\end{array}$ & 40 \\
\hline & & $\begin{array}{l}\text { Superplasticizer BASF Glenium ACE } \\
425\end{array}$ & 32 \\
\hline
\end{tabular}

For the $\mathrm{CC}$ and the SCHPC, the compressive strength $\left(f_{c}\right)$ and the secant modulus of elasticity under compression $\left(E_{c, s}\right)$ were estimated in accordance with standards UNE-EN 12390-3:2009 [34] and UNE-EN 12390-13:2014 [35], respectively. The direct tensile strength $\left(f_{c t}\right)$ of the CC was estimated through $\Phi 100 \times 100 \mathrm{~mm}$ cylindrical specimens with a piston displacement of $1 \mu \mathrm{m} / \mathrm{s}$. The indirect tensile strength $\left(f_{c t, i}\right)$ of the SCHPC was also obtained following the procedure in standard UNE EN 12390-6:2010 [36].

Tests were performed on the CC at 90 days and on the SCHPC at 60 days to be consistent with the age of materials when performing the bond strength tests. The SCHPC was poured on the CC substrates, after 28 of days of curing, and the specimens were then cured for 2 months. The AC substrate specimens were cured for 3 months after pouring the SCHPC.

Table 5. Mechanical characterization of AC, CC and SCHPC.

\begin{tabular}{c|cc|ccccc}
\hline \multirow{2}{*}{ Parameters (MPa) } & \multicolumn{2}{|c|}{ AC } & \multirow{2}{*}{ Age (days) } & \multicolumn{3}{c}{ CC } & \multicolumn{2}{c}{ SCHPC } \\
\cline { 2 - 3 } \cline { 5 - 7 } & Average & C.V. (\%) & & Average & C.V. (\%) & Average & C.V. (\%) \\
\hline \multirow{2}{*}{ Compressive strength } & \multirow{2}{*}{11.38} & 7.10 & 60 & - & - & 101.96 & 8.69 \\
& & - & 90 & 53.62 & 10.29 & - & - \\
\hline Direct tensile strength & - & - & 90 & 2.29 & 25.90 & - & - \\
\hline Indirect tensile strength & 1.890 & 4.48 & 60 & - & - & 6.69 & 16.19 \\
\hline \multirow{2}{*}{ Modulus of elasticity } & \multirow{2}{*}{1520.03} & 23.02 & 60 & - & - & 47,777 & 1.36 \\
& & & 90 & 38,103 & 4.90 & - & - \\
\hline
\end{tabular}

\subsection{Specimen preparation}

Conventional Concrete $(C C)$ and Asphalt Concrete $(A C)$ substrates were molded to prepare the specimens. Surface treatments were applied to the substrates upon which the upper layer of SelfCompacting High-Performance Concrete (SCHPC) was poured. 
The CC substrates were produced following EN 12390-2:2009 [37]. Polyvinyl chloride (PVC) pieces were introduced inside $\Phi 100 \times 200 \mathrm{~mm}$ molds to shape the substrate specimens. The concrete was compacted on a vibrating table. The substrates were kept inside the molds and covered with a plastic sheet for $24 \mathrm{~h}$. They were then stored in a curing camera at a temperature of $20 \pm 1^{\circ} \mathrm{C}$ and at a relative humidity of over $95 \%$ up until the application of the surface treatments.

To produce the AC substrates, ready-mixed asphalt concrete was taken from the supply system of an asphalt hot mix plant. The mix was heated to a temperature of $150{ }^{\circ} \mathrm{C}$ to produce the substrates. They were shaped using cylindrical $\Phi 100 \times 200 \mathrm{~mm}$ molds. In the case of substrates for the DT and the LCB tests, the molds were partially filled (i.e. $100 \mathrm{~mm}$ for DT and $60 \mathrm{~mm}$ for LCB) leaving their upper part empty. Wedge-shaped fiber-reinforced concrete pieces were previously produced for Slant Shear substrates, for placements in molds, to provide the slant plane of the interface. Molds and FRC elements were kept at a temperature of $160{ }^{\circ} \mathrm{C}$ until casting to prevent the fast cooling of the $\mathrm{AC}$. Compaction was conducted using a vibrating hammer with an adapted $\Phi 100 \mathrm{~mm}$ circular plate. The specimens were left to cool inside the molds for 24 hours, after which they were demolded and kept protected from humidity and dust.

The $\mathrm{CBH}$ and the $\mathrm{CBC}$ treatments were conducted after 30 days of casting using a pneumatic needle gun for the bush hammering (Figure 3.a). With regard to the Slant Shear specimens, the roughness was partially implemented on the elliptical surface of the interfaces, leaving $6 \mathrm{~cm}$ from the top vertex untreated (see Figure 2.c). This procedure was followed because the bush-hammering process had broken the top part of the substrates and they were consequently thrown away. The same procedure was adopted for the $\mathrm{AC}$ substrates with $\mathrm{ABH}$ treatment.

\section{< Insert Figure $3>$}

In the $\mathrm{CCP}$ and the $\mathrm{CBC}$ treatments, a primer coating of cement paste was applied to the interface, consisting of CEM I 52,5R cement and 1\% superplasticizer BASF Glenium ACE 425 (approximate watercement ratio of 0.35 ) by weight of cement. The paste was extended over the interfaces just before pouring the fresh SCHPC (Figure 3.b). In the case of the CBC specimens in the SS tests, the untreated surface was 
protected with a $0.2 \mathrm{~mm}$ thick PVC layer to ensure that contact between CC and SCHPC occurred exclusively in the rough area.

In the $A B E$ treatment, surface bitumen was eliminated with the needle gun. Subsequently, a polymer modified bitumen emulsion C60BP3 ADH (according to UNE-EN 13808:2013 [38]) for intercoat adhesion between asphaltic layers was applied with a brush.

The AEG treatment consisted of 2 layers of C65B3 TRG emulsion according to UNE-EN 13808:2013 [38] and 2 layers of 2 - $5 \mathrm{~mm}$ calcareous gravel. The treatment followed a pattern of "emulsion-gravel-emulsion-gravel". The first layer of the emulsion was directly spread with a brush onto the surface of the AC substrate (Figure 4.a). Subsequently, the gravel was dropped onto it and handpressed for firmer packing. The procedure was repeated again for the second layer of bitumen and aggregates.

The SCHPC top layers were produced using disposable molds. These were prepared with $420 \mathrm{x}$ $297 \mathrm{~mm}^{2}$ PVC sheets wrapped around the substrates, thereby forming a hollow cylinder (Figure 4.b). The fresh SCHPC of the overlays was poured into the cylinders. Once again, specimens were covered with a plastic sheet for $24 \mathrm{~h}$ and held in a curing camera until tested.

\section{$<$ Insert Figure $4>$}

\subsection{Experimental set-ups}

Direct Tension (DT) tests were performed with $Ф 100 \times 200 \mathrm{~mm}$ cylindrical specimens consisting of a substrate $100 \mathrm{~mm}$ in height and an overlay $100 \mathrm{~mm}$ in height (Figure 5.a). Tests were done under displacement control at a piston speed of $0.001 \mathrm{~mm} / \mathrm{s}$, in a similar way to [39].

Figure 5.b shows a DT test. The top and bottom surfaces of the specimens were polished before the test. Then, a fast curing adhesive HBM X60 was spread onto the lower load plate and to glue the substrate layer of the specimens. Subsequently, a new layer of adhesive was extended onto the top surface of the specimen. Immediately afterwards, a compressive pre-load of $0.4 \mathrm{kN}$ was applied for 15 
minutes during the hardening of the adhesive and then the test commenced. Special care was taken to centre the specimens and to minimize the likelihood of a skewed load.

\section{$<$ Insert Figure $5>$}

The LCB test consisted of placing a $\Phi 100 \mathrm{~mm}$ specimen in a horizontal position, with two supporting points separated at $188 \mathrm{~mm}$ and a single centered load in the form of a simple supported beam (Figure 5.c). Then, a force that induces shear stress was applied to the interfaces. In this test, the CC and AC substrates were $100 \mathrm{~mm}$ and $60 \mathrm{~mm}$ high, respectively, while the height of all the SCHPC overlays was $100 \mathrm{~mm}$. The different substrate heights were due to the production process was simpler for thinner AC layers. Nevertheless, if the specimens are well clamped into position, this height should not influence the experimental results.

Figure 5.d shows the LCB setup and the test device. A steel $\Phi 100 \times 100 \mathrm{~mm}$ cylindrical element was introduced into the empty part of the test device, to minimize the influence of the height of substrates. The displacement speed of the piston was set at $0.25 \mathrm{~mm} / \mathrm{min}$, in the order of those used in concrete shear tests [40 - 43].

The SS test, based on ASTM C882 [44], consisted of compressive load testing of a composite substrate-overlay specimen with an interface inclined at an angle $\alpha$ to the vertical (Figure 5.e). Tests were conducted with $\Phi 100 \times 200 \mathrm{~mm}$ cylindrical specimens with $\alpha=30^{\circ}$ (Figure 5.f). Substrate and overlay parts had the same geometry, so the specimens were symmetrical. To perform the tests, the specimens were positioned with the substrates on the bottom and the overlays on the top. The loading speed was set at $0.25 \mathrm{MPa} / \mathrm{s}$.

\subsection{Roughness measurement}

The roughness of the bush-hammered interfaces of the $\mathrm{CC}$ substrates with the $\mathrm{CBH}$ and the $\mathrm{CBC}$ treatments intended for Direct Tension and LCB tests was measured to study the relationship between roughness and test results. A procedure based on regulation NLT-335/00 [45] was followed. 
Table 6. Roughness of the interfaces with $C B H$ and $C B C$ treatments.

\begin{tabular}{ccccc}
\hline \multirow{2}{*}{ Treatment } & \multicolumn{4}{c}{ Mean depth (mm) } \\
\cline { 2 - 5 } & Min. & Max. & Average & Std. Dev. \\
\hline CBH & 0.43 & 0.75 & 0.57 & $0.110(19.2 \%)$ \\
\hline CBC & 0.43 & 0.72 & 0.59 & $0.104(17.5 \%)$ \\
\hline
\end{tabular}

The substrates were weighed on scales with an accuracy of $\pm 0.1 \mathrm{~g}$. Limestone sand with a size of $90-129 \mu \mathrm{m}$ and known density was then poured over the rough surfaces and subsequently screeded using a rubber buffer. Then, the specimens with the recently added limestone sand were weighed again. The sand-patch diameters, which corresponded to the transversal area of the substrates, were measured three times, to an accuracy of $0.01 \mathrm{~cm}$, and the actual transversal areas were estimated with the average of the measurements. Finally, the mean depth was calculated as the volume of sand divided by the area of the patch. Table 6 summarizes the results showing that roughness mean depth was similar in both the $\mathrm{CBH}$ and the $\mathrm{CBC}$ treatments.

\section{RESULTS}

\subsection{Failure modes}

Table 7 shows a schematic representation of the three failure types observed in the experimental program: cohesive, adhesive, and mixed mode. Cohesive failure is characterized by cracking outside the interface zone. In other words, the cracks occur in the substrate, not reaching the interface, thus indicating that the strength of the interface is greater than that of the materials of the substrates and overlays. Adhesive failure is characterized by cracking through the interface. In this situation, the interface shows a weaker behaviour in comparison with the substrate and the overlay materials. Finally, mixed failure is a combination of both modes and is caused by the emergence or the rise of secondary stresses or by the existence of different strength capacity zones along the interface.

Table 8 shows the number of specimens, by type of substrate and by treatment, that were tested, the number of statistically accepted results for the bonding strength analysis, and the number of 
specimens which presented cohesive, adhesive, and mixed failure. The acceptance or rejection of the test results was done through the statistical Chauvenet's test [46].

Table 7. Failure modes in Direct Tensile (DT), LCB, and Slant Shear (SS) tests.

\begin{tabular}{lccc}
\hline \multirow{2}{*}{ Test } & \multicolumn{3}{c}{ Failure types } \\
\cline { 2 - 4 } Direct Tensile & Cohesive & Adhesive & Mixed \\
\hline & & & \\
\hline
\end{tabular}

Table 8. Number of specimens tested, statistically accepted and failure mode.

\begin{tabular}{|c|c|c|c|c|c|c|c|c|c|c|c|c|c|}
\hline \multicolumn{7}{|c|}{ Conventional Concrete Substrate (CC) } & \multicolumn{7}{|c|}{ Asphalt Concrete Substrate (CC) } \\
\hline \multirow[b]{2}{*}{ Treatment } & \multirow[b]{2}{*}{ Test } & \multicolumn{5}{|c|}{ Number of specimens } & \multirow[b]{2}{*}{ Treatment } & \multirow[b]{2}{*}{ Test } & \multicolumn{5}{|c|}{ Number of specimens } \\
\hline & & 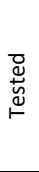 & 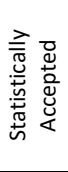 & 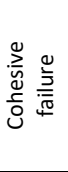 & 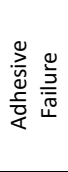 & 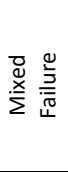 & & & 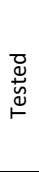 & 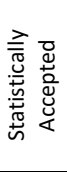 & 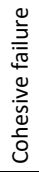 & 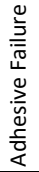 & 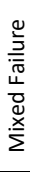 \\
\hline \multirow{3}{*}{ CNP } & DT & 6 & 6 & 0 & 6 & 0 & \multirow{3}{*}{ ANP } & DT & 6 & 5 & 6 & 0 & 0 \\
\hline & LCB & 6 & 6 & 0 & 4 & 2 & & LCB & 6 & 5 & 2 & 0 & 4 \\
\hline & SS & 6 & 6 & 0 & 6 & 0 & & SS & 4 & 4 & 4 & 0 & 0 \\
\hline \multirow{3}{*}{ CCP } & DT & 6 & 5 & 0 & 6 & 0 & \multirow{3}{*}{$\mathrm{ABH}$} & DT & 6 & 5 & 0 & 5 & 1 \\
\hline & LCB & 6 & 6 & 0 & 5 & 1 & & LCB & 6 & 6 & 0 & 6 & 0 \\
\hline & SS & 6 & 6 & 0 & 6 & 0 & & SS & 3 & 3 & 0 & 2 & 1 \\
\hline \multirow{3}{*}{$\mathrm{CBH}$} & DT & 6 & 6 & 0 & 6 & 0 & \multirow{3}{*}{$\mathrm{ABE}$} & DT & 6 & 5 & 0 & 6 & 0 \\
\hline & LCB & 6 & 5 & 0 & 5 & 1 & & LCB & 6 & 5 & 0 & 6 & 0 \\
\hline & SS & 6 & 5 & 0 & 6 & 0 & & SS & 1 & 1 & 0 & 1 & 0 \\
\hline \multirow{3}{*}{$\mathrm{CBC}$} & DT & 6 & 5 & 0 & 6 & 0 & \multirow{3}{*}{ AEG } & DT & 6 & 5 & 0 & 6 & 0 \\
\hline & LCB & 6 & 4 & 0 & 5 & 1 & & LCB & 6 & 5 & 0 & 6 & 0 \\
\hline & SS & 6 & 5 & 0 & 6 & 0 & & SS & - & - & - & - & - \\
\hline
\end{tabular}

In the case of specimens with the CC substrate, the failure in all cases under Direct Tensile (DT) and Slant Shear (SS) tests was adhesive. It means that we may directly consider the test values as the actual strength of the interfaces. Furthermore, in SS tests the type of failure may depend on the angle of 
the interface (bigger angles induce cohesive failures), so the selection of $\alpha=30^{\circ}$ was adequate. Both adhesive and mixed modes occurred in the shear LCB test. In specimens with mixed failure the size of the adhered material was measured following the same methodology as in [40]. According to this methodology, all LCB data was accepted for the statistical analysis. Then, the strengths that were obtained were assumed to be those of the interfaces.

In contrast, 3 types of failures occurred with the AC substrate specimens. With the ANP treatment, no adhesive failure occurred and 12 of 16 specimens presented a cohesive break. Contrarily, with $A B E, A E G$ and $A B H$ no cohesive failures took place. This indicates that direct pouring of the selfcompacting SCHPC results in a higher bonding strength than the last three treatments. The mixed failures of $\mathrm{ABH}$ were obtained in a single DT test specimen that did not meet Chauvenet's criterion and in one SS specimen.

\subsection{Bond strength between CC and SCHPC}

Figures 6.a, b, and c show typical Stress-Displacement curves for specimens with the Conventional Concrete (CC) substrate in the Direct Tension (DT), the LCB, and the Slant Shear (SS) tests, respectively. In all treatments, fragile behaviour was found with an immediate drop of the load once the maximum was reached. The slope of the curve varies for low load/strength ratios, presumably due to the adjustments of the components of the loading equipment. After that, an almost perfectly linear tendency is followed with no reduction of the slope until failure.

\section{< Insert Figure $6>$}

Figure 6.d shows the averages and typical deviation of the results of the DT tests. The maximum average value (1.20 MPa) corresponds to the CNP treatment, followed by the $\mathrm{CBH}$ treatment with a similar strength (1.06 MPa). The CCP $(0.57 \mathrm{MPa})$ and the $\mathrm{CBC}(0.65 \mathrm{MPa})$ treatments showed approximately half the strength of the CNP treatment. In the CNP and the CBH treatments, the SCHPC overlay was directly poured onto smooth and rough interfaces, respectively. In contrast, the SCHPC was poured over the cement paste in the CCP and the CBC treatments. These results show that pure tensile strength was mostly 
due to chemical bonding between layers. As suggested in [47], roughness has an almost negligible effect, because failure is mainly related to normal stresses.

Figure 6.e shows the experimental results of the LCB tests. The CBC treatment had a higher average strength $(5.22 \mathrm{MPa})$, although similar to the $\mathrm{CBH}(4.92 \mathrm{MPa})$ treatment. The CNP treatment presented a slightly lower strength (4.46 MPa), although quite similar to the strength of both the $\mathrm{CBC}$ and the $\mathrm{CBH}$ treatments. In the case of the $\mathrm{CCP}$ treatment, the strength decreased to $2.90 \mathrm{MPa}$ on average. The best results were obtained with the rough interface ( $C B C$ and $C B H$ ) with a minimal influence of the cement paste on the strength. In contrast, when the interface was smooth (CNP and CCP), the strength was mainly due to chemical bonding. The cement paste created weak points in the interface, while the direct pouring of the SCHPC created a chemical bond equivalent to roughening. All these results indicated that roughness plays the main role in pure shear strength.

Regarding the SS tests, Figure 6.f illustrates the results of compressive stress applied to the top and the bottom faces of the specimens. The values of the applied load were multiplied by 1,337 to calculate the stresses in both the $\mathrm{CBH}$ and the $\mathrm{CBC}$ specimens. It considers that interface areas were reduced. The possible influence of load eccentricities was neglected. In general, similar behaviour to that found in LCB tests was obtained. Treatments CNP, CBH, and CBC were statistically similar (average results of 49.19, 45.00 and 51.14 MPa, respectively), while treatment CCP had five times less strength (8.60 MPa).

The shear forces predominated over the normal ones due to the angle of the interface and friction played a relevant role. Consequently, the strengths of both the $\mathrm{CBH}$ and the $\mathrm{CBC}$ treatments were similar, because resistance to the shear stresses was mainly due to roughness. In the case of the CNP treatment, the effects of the chemical bonding of the SCHPC slurry obtained similar results, equivalent to a rougher interface. Conversely, the CCP cement paste contributed negatively, since its adhesive power was far lower than that of the SCHPC.

The relations between roughness and the DT and the LCB test results were also studied. Figures 7.a and $b$ show the DT and the LCB test results, respectively, in terms of the mean depth of the rough surface of the specimens that were tested. 
Overall, high dispersion and no correlation between depth and pure tension and shear strength were observed. Furthermore, the DT results showed a wider scatter than the LCB ones, probably because of the intrinsic dispersion of both tests. On the other hand, Figure 7.a shows again that the cement paste clearly reduces the DT strength, because chemical adhesion is the key factor. Contrarily, Figure 7.b illustrates similar results that were obtained with both treatments, pointing to the central effects of roughness.

\subsection{Bond strength between AC and SCHPC}

Figures 8.a, b and c present the typical Load-Displacement curves for the Direct Tension (DT), the LCB and the Slant Shear (SS) tests, respectively. Unlike the specimens with the CC substrate, the curves presented a ductile-softening behaviour. After the maximum strength point, small cracks incrementally appeared and grew until total failure. The asphalt concrete resisted the stresses during the softening process.

Figure 8.d presents the results of the Direct Tensile test for the four treatments. The strength of the ANP specimens (1.61 MPa) was considered to be $85 \%$ of the indirect tensile strength of the asphalt substrate $\left(f_{a c t, i}\right)$, because all ANP specimen failures passed through the AC substrate. Treatments $A B H, A B E$ and $A E G$ all failed through the interface, showing tensile strengths of $0.27,0.49$ and $0.23 \mathrm{MPa}$, respectively.

The high strength of the ANP treatment was due to the interlocking effect produced by the penetration of the SCHPC into the AC surface pores. This effect was not obtained with the ABH treatment because bush-hammering eliminated the superficial pores, leaving a rough surface with little porosity. In the case of the $A B E$ treatment, the bituminous emulsion acted as a chemical bonding bridge the adhesive power of which was higher than the increased roughness. Finally, the AEG specimens failed, because the bituminous emulsion became unglued, although they were of a similar strength to the $\mathrm{ABH}$ treatment. So, the ANP treatment is recommended for porous AC substrate surfaces to resist direct tensile stresses. 
The LCB test results are shown in Figure 8.e. The maximum shear strength was also achieved with the ANP treatment (1.12 MPa), due to the penetration of the SCHPC into the pores. No great difference was observed between the results for either the $\mathrm{ABH}$ or the $\mathrm{ABE}$ ( 0.82 and $0.80 \mathrm{MPa}$, respectively) treatments. Once again, the AEG treatment had the lowest strengths (0.34 MPa).

The $\mathrm{ABH}$ treatment had $73.2 \%$ of the strength of the ANP treatment in this test while the strength of the DT treatment was only $16.8 \%$. This result suggests that roughness appears to play a key role in the shear behaviour. Nevertheless, the strength was not as great as that obtained with the ANP treatment, because there was no SCHPC interlock. As regards the ABE treatment, the chemical bonding obtained with the bituminous emulsion was equivalent to the bonding obtained by roughening the interface. In the case of the AEG treatment, the chemical bonding power of the emulsion was small, so the strength was only $42.5 \%$ of that obtained with the ABE treatment. Consequently, the ANP treatment is also the best surface preparation for pure shear stresses.

Finally, Figure $8 . f$ shows the SS results considering the reduced interface area of the $A B H$ interfaces. Due to the limited number of specimens, the results are presented as qualitative information for guidance. The ANP strength (5.22 MPa) was a lower value of the strength of the interface, because all failures were located in the asphalt substrates. In the case of the ABH treatment, 1 of the 3 specimens suffered mixed failure, so its strength (6.25 MPa) corresponded to a limit situation between failure of the substrate and failure through the interface. The $\mathrm{ABH}$ strength was therefore close to that of the substrates. Its slightly higher strength than ANP might be explained by the dispersion of the asphalt substrate strength and the intrinsic dispersion of the SS test. As regards the single EBA specimen, its strength was 3.16 MPa with failure along the interface, which would suggest that this value might correspond to the actual strength of the interface.

\section{CONCLUSIONS}

In this extensive experimental program, bonding behaviours between Self-Compacting HighPerformance Concrete (SCHPC) overlays and substrates made with Conventional Concrete (CC) and 
Asphalt Concrete (AC) have all been analyzed. Direct Tension (DT), pure shear LCB (LCB) and compressive Slant Shear (SS) tests have been performed. The following conclusions have been drawn from the study:

- In the case of specimens with CC substrate, all treatments presented fragile behaviour in the three tests. In the DT tests, the best results were obtained with the CNP treatment, while the CBC treatment had higher strengths in both the LCB and the SS tests. Nevertheless, both the CNP and the $\mathrm{CBC}$ treatments presented similar strengths in both the LCB and the SS tests; indicating that direct pouring of the SCHPC requires no additional actions. It is explained due to both the capacity of the self-compacting SCHPC to adapt to the interface irregularities and the absence of a bonding bridge that can induce weak points. Relationships between roughness and the results of the DT and the LCB tests were also studied in both the $\mathrm{CBH}$ and the $\mathrm{CBC}$ treatments and no evident correlation was observed.

- For specimens with AC substrate, all treatments showed ductile-softening behaviour in the three tests. The ANP treatment was the only one to show cohesive failures in the three types of tests, due to the penetration of the SCHPC in the pores of the asphalt. In the DT and the LCB tests, the ANP treatment showed the highest strengths, while the $\mathrm{ABH}$ treatment achieved the highest strength in the SS test, although an almost similar strength was obtained with the ANP treatment. Consequently, the ANP treatment showed the best overall performance.

- Roughness had different impacts on the bonding behaviour, depending on the type of tests and substrate material. In the case of the CC substrates, roughness has an almost negligible effect on Direct Tensile strength, because it is related to the chemical bonding. Contrarily, roughness plays the main role in pure shear LCB tests. In the case of the SS tests, shear forces predominated over normal ones and friction (roughness) has also a relevant role. Regarding the AC substrates, the roughening process eliminated the superficial pores of the interface, so the interlocking effect between substrates and SCHPC did not occur. Due to the absence of an interlocking effect, the DT, SS, and LCB strengths are reduced. In the case of the LCB test, the reduction was less dramatic than in the DT tests, because the roughness provided friction strength. Finally, in the case of the SS tests, the slightly higher strength obtained with roughened surfaces is explained, because the 
specimens failed in an intermediary situation between failure of the substrate and failure through the interface.

\section{Acknowledgements}

The authors wish to thank the Ministerio de Economía y Competitividad for financial support provided through project SAES (BIA2016-78742-C2-1-R) and are grateful to Janill de la Cruz for her assistance with the experimental work. The first author also acknowledges the grant FI-DGR 2015 provided by the Agència de Gestió d'Ajuts Universitaris i de Recerca of the Generalitat de Catalunya.

\section{REFERENCES}

1. American Concrete Pavement Association, Guide to concrete overlays: sustainable solutions for resurfacing and rehabilitating existing pavements, Third ed., ACPA, Publication TB021.02, 2014.

2. H.N. Torres, J. Roesler, R.O. Rasmussen, D. Harrington, Guide to the Design of Concrete Overlays Using Existing Methodologies, lowa State University, National Concrete Pavement Technology Center, 2012.

3. R.O. Rasmussen, D.K. Rozycki, Thin and ultra thin whitetopping - a synthesis of highway practice NCHRP synthesis 338, Transport. Res. Board (2004).

4. A.M. Diab, A.E.M.A. Elmoaty, M.R.T. Eldin, Slant shear bond strength between self compacting concrete and old concrete, Constr. Build. Mat. 130 (2017) 73-82.

5. C. Schmidt, M. Schmidt, "Whitetopping" of asphalt and concrete pavements with thin layers of Ultra-High-Performance Concrete: Construction and economic efficiency, Proceedings of 3rd International Symposium on UHPC and Nanotechnology for High Performance Construction Materials, 2012, pp. 921-927. Kassel (Germany).

6. M.E. Mohamad, I.S. Ibrahim, R. Abdullah, A.A. Rahman, A.B.H. Kueh, J. Usman, Friction and cohesion coefficients of composite concrete-to-concrete bond, Cement Concrete Comp. 56 (2015) 1-14. 
7. M. Rith, Y.K. Kim, S.W. Lee, J.Y. Park, S.H. Han, Analysis of in situ bond strength of bonded concrete overlay, Constr. Build. Mat. 111 (2016) 111-118.

8. D.S. Santos, P.M. Santos, D. Dias-da-Costa, Effect of surface preparation and bonding agent on the concrete-to-concrete interface strength, Constr. Build. Mat. 37 (2012) 102-110.

9. E.N. Julio, F.A. Branco, V.D. Silva, Concrete-to-concrete bond strength. Influence of the roughness of the substrate surface, Constr. Build. Mat. 18 (9) (2004) 675-681.

10. A. Momayez, M.R. Ehsani, A.A. Ramezanianpour, H. Rajaie, Comparison of methods for evaluating bond strength between concrete substrate and repair materials, Cement Concrete Res. 35 (4) (2005) 748-757.

11. A.D. Espeche, J. León, Estimation of bond strength envelopes for old-to-new concrete interfaces based on a cylinder splitting test, Constr. Build. Mat. 25 (3) (2011) 1222-1235.

12. C. Zanotti, N. Banthia, G. Plizzari, A study of some factors affecting bond in cementitious fiber reinforced repairs, Cement Concrete Res. 63 (2014) 117-126.

13. B.A. Tayeh, B.A. Bakar, M.M. Johari, M.M. Ratnam, The relationship between substrate roughness parameters and bond strength of ultra high-performance fiber concrete, J. Adhes. Sci. Technol. 27 (16) (2013) 1790-1810.

14. M.A. Carbonell Muñoz, D.K. Harris, T.M. Ahlborn, D.C. Froster, Bond performance between ultra high-performance concrete and normal-strength concrete, J. Mater. Civil Eng. 26 (8) (2013) 04014031.

15. M. Roy, I. Ray, J.F. Davalos, High-performance fiber-reinforced concrete: Development and evaluation as a repairing material, J. Mater. Civil Eng. 26 (10) (2013) 04014074.

16. Z. Leng, H. Ozer, I. Al-Qadi, S. Carpenter, Interface bonding between hot-mix asphalt and various Portland cement concrete surfaces: laboratory assessment, Transport Res. Rec. 2057 (2008) 4653.

17. A. Chabot, M. Hun, F. Hammoum, Mechanical analysis of a mixed mode debonding test for “composite" pavements, Constr. Build. Mat. 40 (2013) 1076-1087. 
18. F. Isla, B. Luccioni, G. Ruano, M.C. Torrijos, F. Morea, G. Giaccio, R. Zerbino, Mechanical response of fiber reinforced concrete overlays over asphalt concrete substrate: Experimental results and numerical simulation, Constr. Build. Mat. 93 (2015) 1022-1033.

19. F. Mu, Laboratory and Numerical Investigation of Interface Debonding of Bonded Concrete Overlay of Asphalt and Its Effects on the Critical Stress in the Overlay (Ph.D. dissertation), Swanson School of Engineering, University of Pittsburgh, 2014.

20. J.L. Granju, V. Sabathier, A. Turatsinze, A. Toumi, Interface between an old concrete and a bonded overlay: debonding mechanism, Interface Sci. 12 (4) (2004) 381-388.

21. A. Turatsinze, H. Beushausen, R. Gagné, J.L. Granju, J. Silfwerbrand, R. Walter, Debonding, in: B. Bissonnette, L. Courard, D.W. Fowler, J.L. Granju (Eds.), Bonded Cement-Based Material Overlays for the Repair, the Lining or the Strengthening of Slabs or Pavements, Springer Netherlands, 2011, pp. 107-139.

22. M.A. Chestney, Concrete Patch Repair Bond Strength, Department of Civil and Building Engineering, Loughborough University, 1996.

23. J.G. Teng, S.T. Smith, J. Yao, J.F. Chen, Intermediate crack-induced debonding in RC beams and slabs, Constr. Build. Mat. 17 (6) (2003) 447-462.

24. F. Perez, B. Bissonnette, R. Gagné, Parameters affecting the debonding risk of bonded overlays used on reinforced concrete slab subjected to flexural loading, Mater. Struct. 42 (5) (2009) 645662.

25. H.E. Yucel, H. Jashami, M. Sahmaran, M. Guler, I.O. Yaman, Thin ECC overlay systems for rehabilitation of rigid concrete pavements, Mag. Concrete Res. 65 (2) (2013) 108-120.

26. M. Hun, A. Chabot, F. Hammoum, A four-point bending test for the bonding evaluation of composite pavement, RILEM Bookseries, vol. 4, 2012, pp. 51-60.

27. R. Miró, F. Pérez, J.M. Borrás, Evaluation of the effect of tack coats. LCB shear test, in: M.N. Partl (Ed.), Proceedings of Sixth International RILEM Symposium on Performance Testing and Evaluation of Bituminous Materials, 2003, pp. 550-556. Zurich (Switzerland).

28. R. Miró, A. Martínez, F. Pérez, Assessing heat-adhesive emulsions for tack coats, P. I. Civil Eng. Transp. 158 (2005) 45-51. 
29. UNE-EN 13108-1:2008, Bituminous mixtures. Material Specifications. Part 1: Asphalt concrete, 2008.

30. UNE-EN 12591:2009. Bitumen and bituminous binders. Specifications for paving grade bitumen, 2009.

31. A. Aguado de Cea, S. Carrascón, S.H. Pialarissi Cavalaro, I. Puig Damians, C. Senés, Manual para el proyecto, construcción y gestión de pavimentos bicapa de hormigón, Instituto Español del Cemento y sus Aplicaciones, 2010 (Only available in Spanish).

32. NLT-161/98, Simple compression strength of asphalt mixtures. NLT Standards, 1998 (Only available in Spanish).

33. NLT-346/90, Indirect tensile strength of bituminous mixes, NLT Standards, 1990 (Only available in Spanish).

34. UNE EN 12390-3:2009. Testing hardened concrete - Part 3: Compressive strength of test specimens, 2009.

35. UNE-EN 12390-13:2014. Testing hardened concrete - Part 13: Determination of secant modulus of elasticity in compression, 2014.

36. UNE EN 12390-6:2010. Testing hardened concrete - Part 6: Tensile splitting strength of test specimens, 2010.

37. UNE EN 12390-2:2009. Testing hardened concrete - Part 2: Making and curing specimens for strength tests, 2009.

38. UNE-EN 13808:2013. Bitumen and bituminous binders - Framework for specifying cationic bituminous emulsions, 2013.

39. C. Czaderski, K. Soudki, M. Motavalli, Front and side view image correlation measurements on FRP to concrete pull-off bond tests, J. Compos. Constr. 14 (4) (2010) 451-463.

40. L. Segura-Castillo, A. Aguado de Cea, Bi-layer diaphragm walls: Evolution of concrete-to-concrete bond strength at early ages, Constr. Build. Mat. 31 (2012) 29-37.

41. I. Ray, J. Davalos, S. Luo, Interface evaluations of overlay-concrete bi-layer composites by a direct shear test method, Cement Concrete Comp. 27 (2005) 339 - 347. 
42. A.A. Mirsayah, N. Banthia, Shear strength of steel fiber-reinforced concrete, ACl Mater. J. 99 (2002) 473-479.

43. J. Wall, N. Shrive, Factors affecting bond between new and old concrete, ACl Mater. J. 85 (2) (1988) 117-125.

44. ASTM C 882-13a. Standard test method for bond strength of epoxy-resin systems used with concrete by slant shear, 2013.

45. NLT-335/00, Measurement of the surface macrotexture of a pavement using the volumetric technique, NLT Standards, 2000 (Only available in Spanish).

46. J.R. Taylor, An introduction to error analysis - the study of uncertainties in physical measurements, second ed., University Science Books, 1997, Sausalito, California, USA, p. 349.

47. I. Iovinella, A. Prota, C. Mazzotti, Influence of surface roughness on the bond of FRP laminates to concrete, Constr. Build. Mat. 40 (2013) 533-542. 


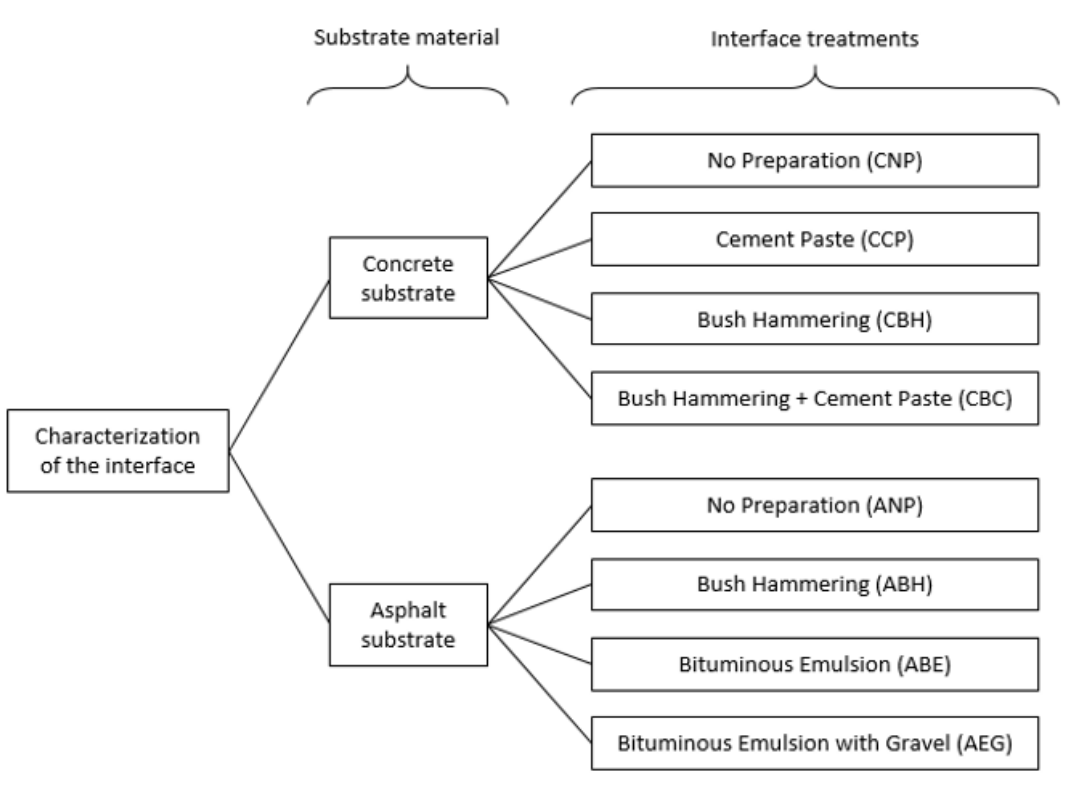

Figure 1. Variables considered for the strength characterization of the interface. 


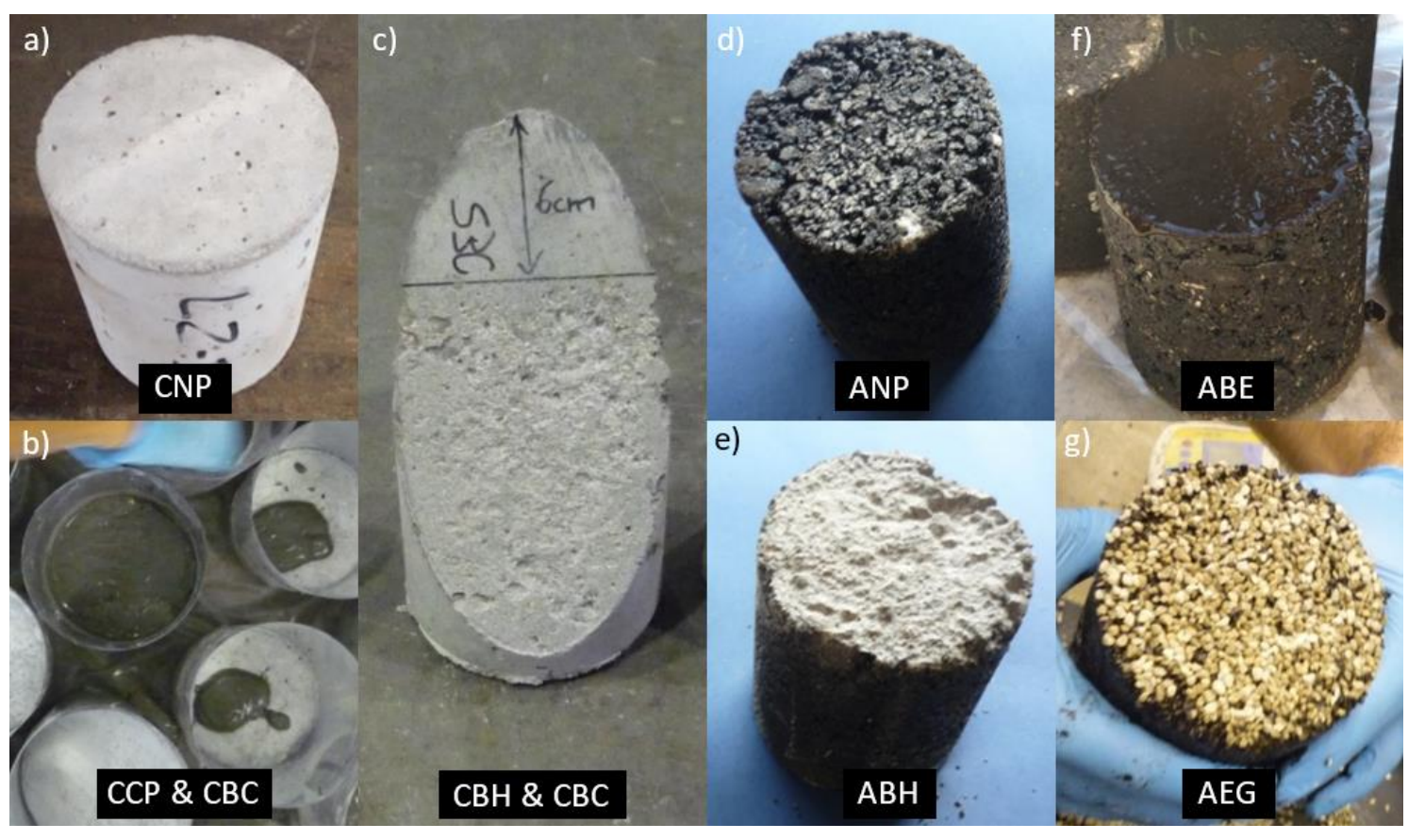

Figure 2. Appearance of the surface treatments. 

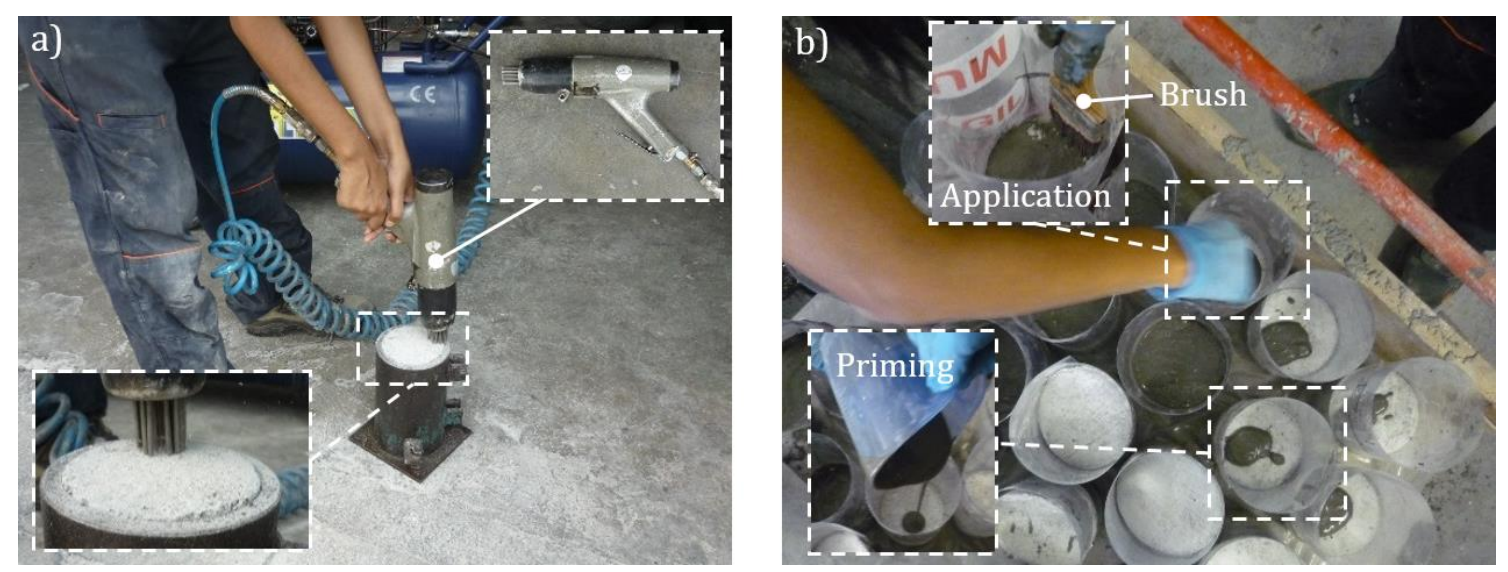

Figure 3. Bush-hammering of the cylindrical CC substrates (a). Application of the cement paste (b). 

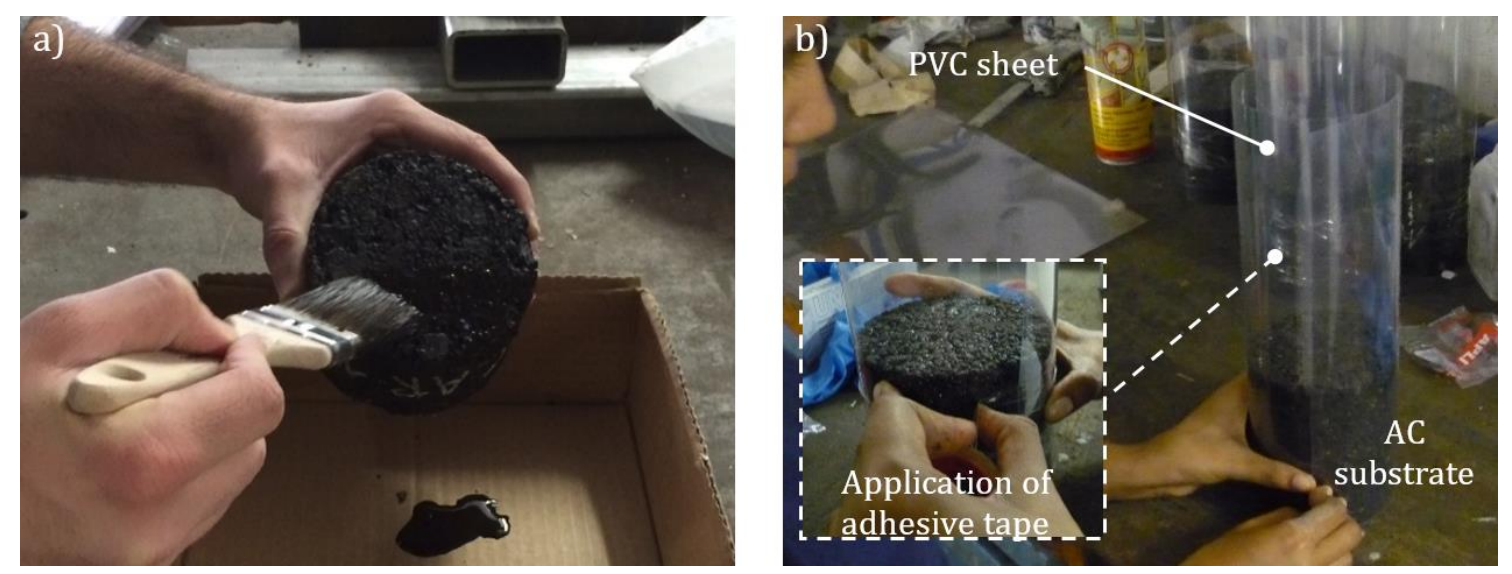

Figure 4. Application of bitumen emulsion (a). Preparing the molds for the SCHPC overlay (b). 

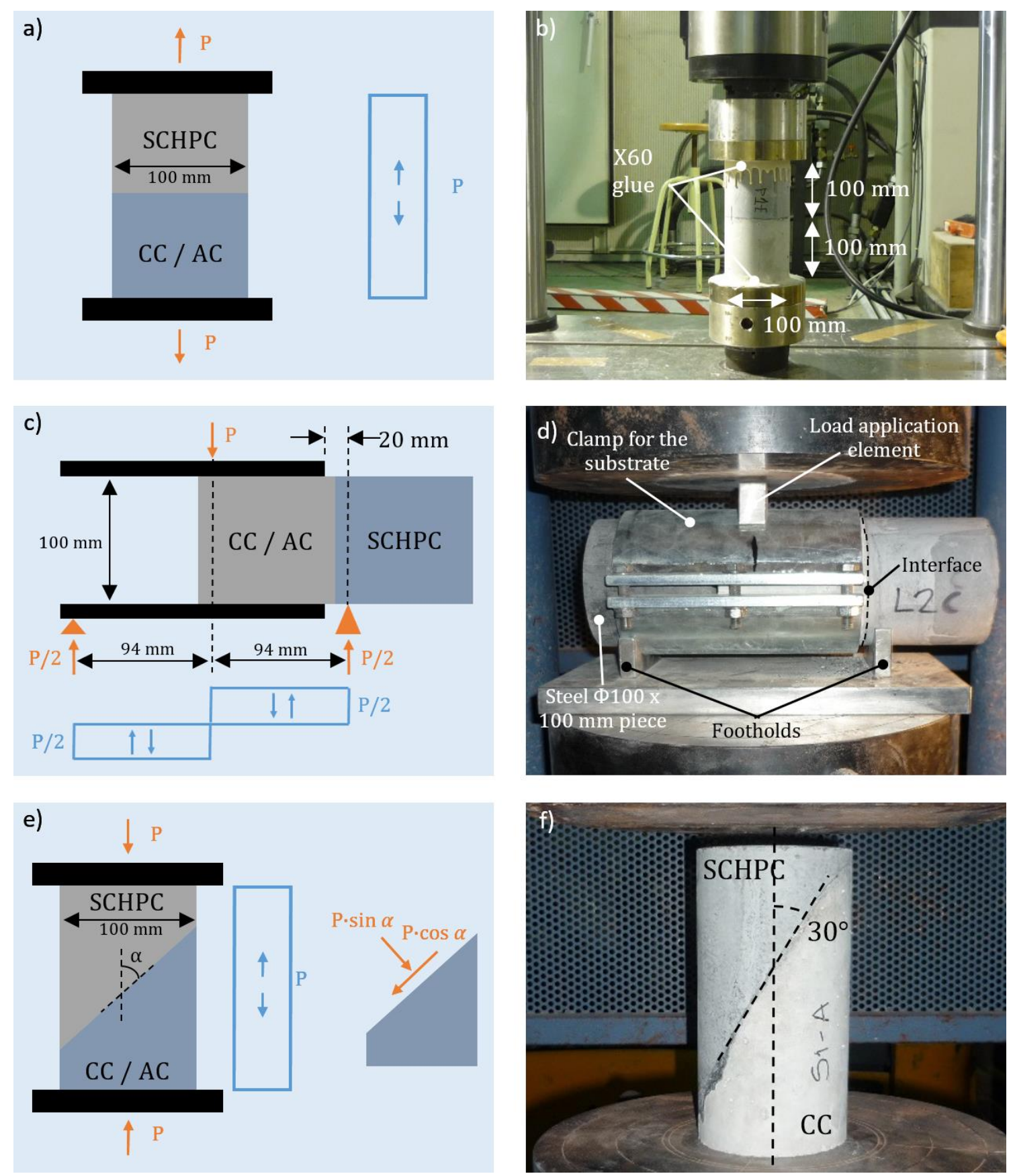

Figure 5. Configuration and load schemes of: Direct Tension (DT) test (a, b), LCB test (c, d) and Slant Shear (SS) test $(e, f)$. 

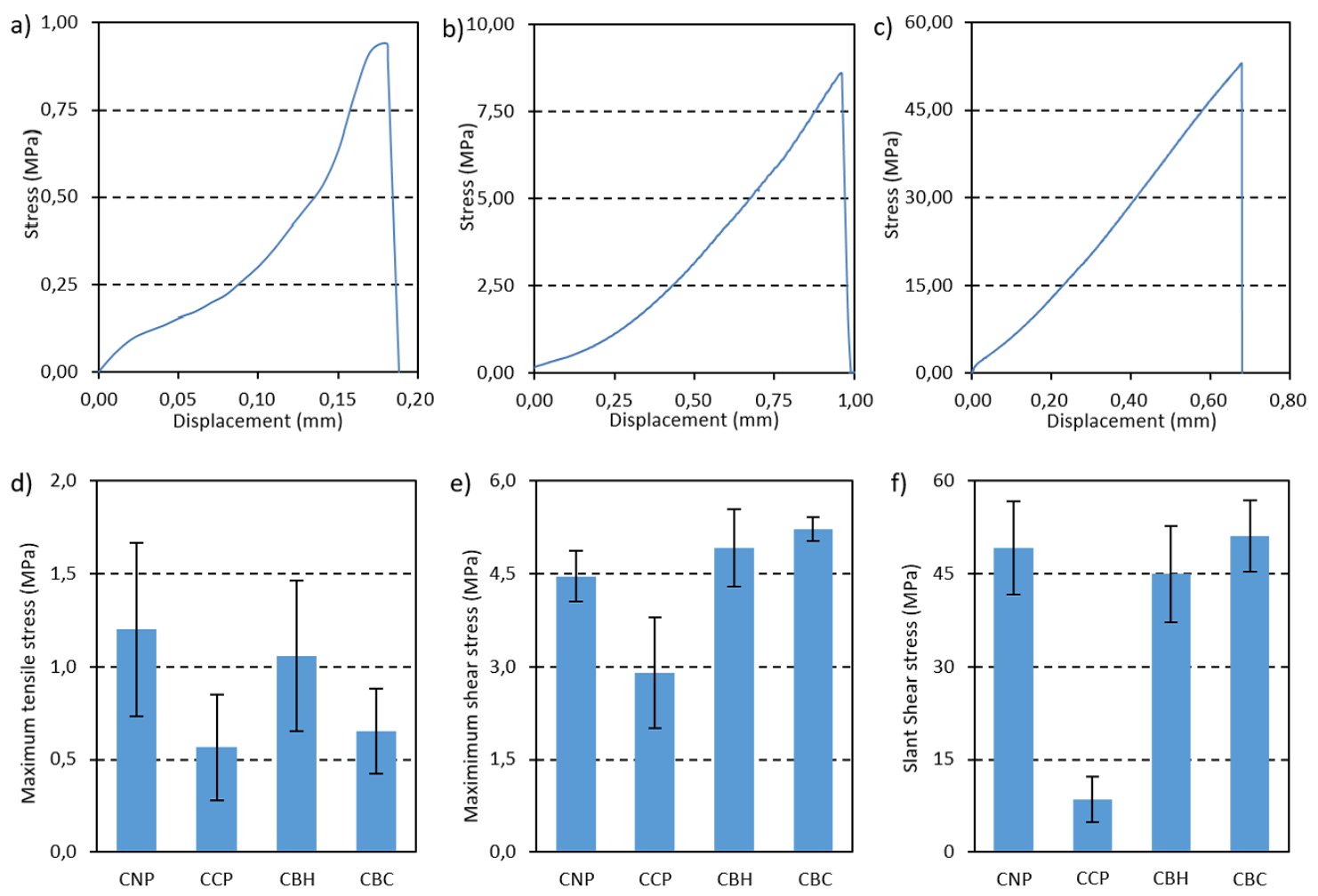

Figure 6. CC substrate specimens: Typical Load-Displacement curves under DT (a), LCB (b) and SS (c) tests and experimental results of DT (d), LCB (e) and SS (f) tests. 

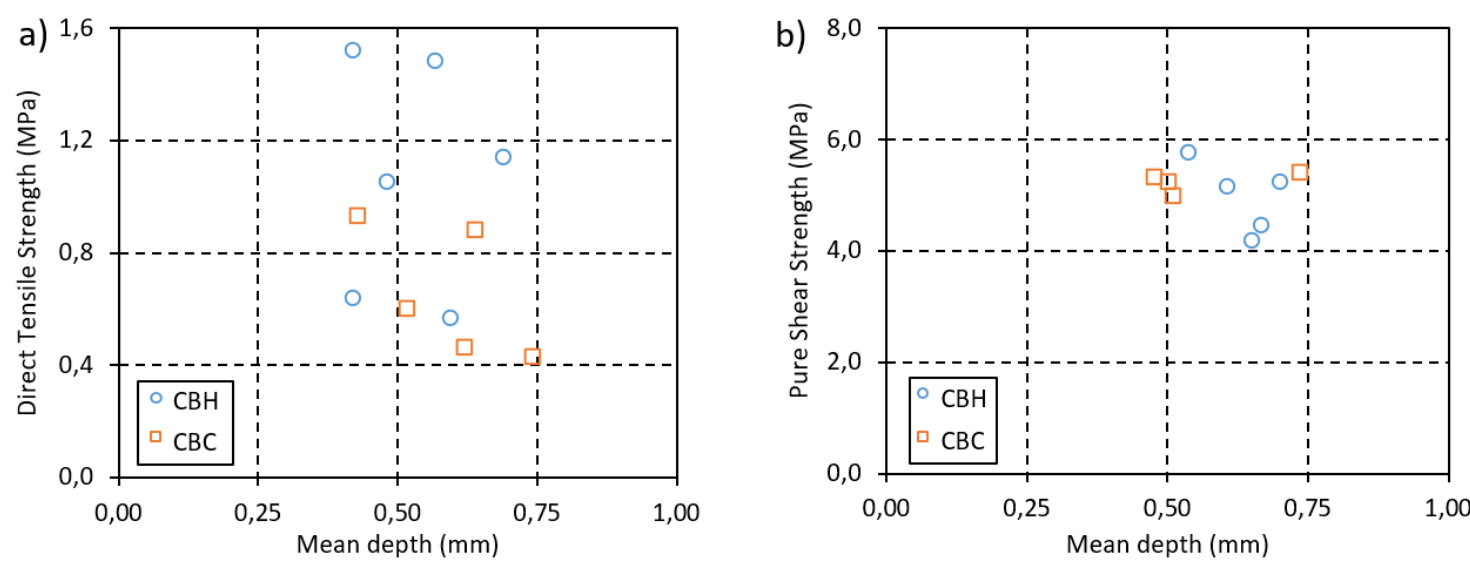

Figure 7. Relation between roughness and test results: Direct Tensile (DT) (a) and LCB (b) tests. 

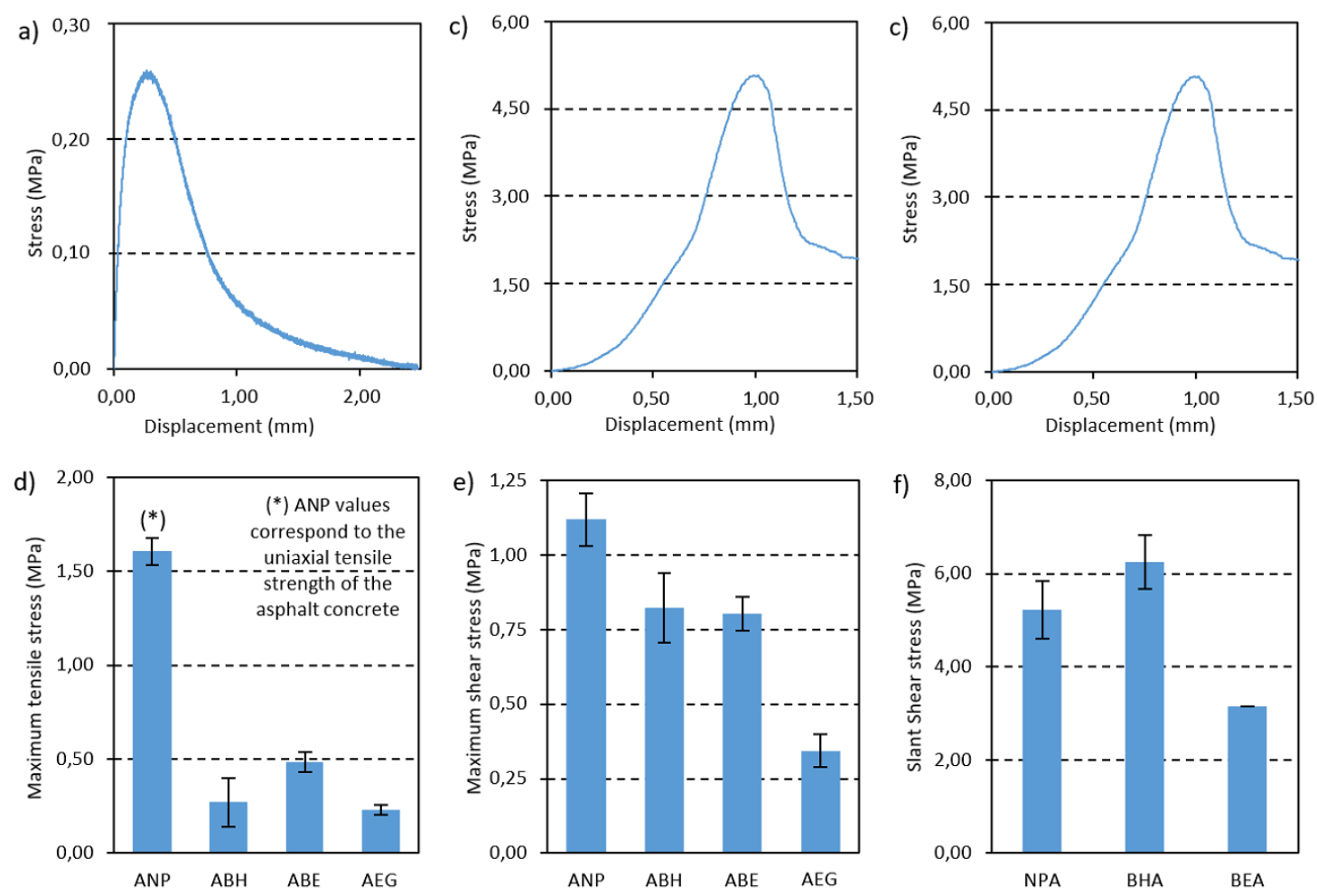

Figure 8. Typical Load-Displacement curves under DT (a), LCB (b) and SS (c) tests and experimental results of DT (d), LCB (e) and SS (f) tests. 